\title{
Best Protocol for the Sit-to-Stand Test in Subjects With COPD
}

\author{
Andrea A Morita MSc, Gianna W Bisca PhD, Felipe V C Machado PT, Nidia A Hernandes PhD, \\ Fabio Pitta PhD, and Vanessa S Probst PhD
}

\begin{abstract}
BACKGROUND: Different protocols for the sit-to-stand test (STS) are available for assessing functional capacity in COPD. We sought to correlate each protocol of the STS (ie, the 5-repetition [5-rep STS], the 30-s STS, and the 1-min STS) with clinical outcomes in subjects with COPD. We also aimed to compare the 3 protocols of the STS, to verify their association and agreement, and to verify whether the 3 protocols are able to predict functional exercise capacity and physical activity in daily life (PADL). METHODS: 23 subjects with COPD (11 men; FEV $_{1} 53 \pm 15 \%$ predicted) performed 3 protocols of the STS. Subjects also underwent the following assessments: incremental shuttle walking test, 6-min walk test (6MWT), 4-m gait speed test (4MGS), 1-repetition maximum of quadriceps muscle, assessment of PADL, and questionnaires on health-related quality of life and functional status. RESULTS: The 1-min STS showed significant correlations with the 6MWT $(r=0.40)$, 4MGS $(r=0.64)$, and PADL $(0.40 \leq \mathrm{r} \leq 0.52)$, and the 5-rep STS and 30-s STS were associated with the 4MGS $(\mathrm{r}=0.54$ and $\mathbf{r}=0.52$, respectively). The speed differed for each protocol (5-rep STS $0.53 \pm 0.16 \mathrm{rep} / \mathrm{s}, 30$-s STS $0.48 \pm 0.13 \mathrm{rep} / \mathrm{s}, 1-\mathrm{min}$ STS $0.45 \pm 0.11 \mathrm{rep} / \mathrm{s}, P=.01)$. However, they presented good agreement (intraclass correlation coefficient $\geq 0.73$ for all) and correlated well with each other ( $r \geq 0.68$ for all). More marked changes in peripheral oxygen saturation $(P=.004)$, heart rate $(P<.001)$, blood pressure $(P<.001)$, dyspnea $(P<.001)$, and leg fatigue $(P<.001)$ were found after the 1 -min STS protocol. Furthermore, the 3 protocols were equally able to identify subjects with low exercise capacity or preserved exercise capacity. CONCLUSIONS: The 1-min STS generated higher hemodynamic demands and correlated better with clinical outcomes in subjects with COPD. Despite the difference in speed performance and physiological demands between the 5-rep STS and 1-min STS, there was a good level of agreement among the 3 protocols. In addition, all 3 tests were able to identify subjects with low exercise capacity or preserved exercise capacity. Key words: pulmonary disease; chronic obstructive; exercise test; motor activity; activities of daily living; hemodynamics; patient outcome assessment. [Respir Care 2018;63(8):1040-1049. (C) 2018 Daedalus Enterprises]
\end{abstract}

\section{Introduction}

It is well known that COPD is described as a systemic disease and not just pulmonary impairment. Extrapulmonary effects, such as muscle dysfunction, cardiovascular and metabolic disorders, ${ }^{1}$ and decreased functional capac-

\footnotetext{
The authors are affiliated with the Laboratory of Research in Respiratory Physiotherapy, Department of Physiotherapy, State University of Londrina, Londrina, Brazil.

Ms Morita presented a version of this paper at the 25th Annual Congress of the European Respiratory Society, held September 26-30, 2015, in Amsterdam, The Netherlands.
}

The authors have disclosed no conflicts of interest. ity are potential risk factors for health status decline over time. ${ }^{2}$ Considering these factors, a marked impairment observed in patients with COPD is a functional capacity limitation. This condition implies constraints in basic physical actions. ${ }^{3}$ For this reason, assessment of functional capacity is extremely important and necessary. ${ }^{4}$

\footnotetext{
Correspondence: Vanessa Suziane Probst PhD, Departamento de Fisioterapia, Centro de Ciências da Saúde, Hospital Universitário de Londrina, Avenida Robert Koch, 60 Vila Operária, 86038-350, Londrina, Paraná, Brazil. E-mail: vanessaprobst@gmail.com.
}

DOI: $10.4187 /$ respcare.05100 
One of the most common and reliable tools for assessing functional capacity in patients with COPD is the 6-min walk test (6MWT). ${ }^{5,6}$ Although it is considered a simple test, it requires space, time, and trained staff. 5 To overcome these barriers, recent studies have suggested the use of the sit-to-stand test (STS) as an alternative in this population. The STS and the 6MWT correlate well with each other and show similar results, such as in hemodynamic response and symptoms, supporting the STS as an option..$^{7,8}$

The STS is a simple and practical test, widely adopted to evaluate functionality in community-dwelling elderly. ${ }^{9-11}$ The movement of standing up and sitting down are important functions of daily life, and the inability to perform these basic skills is associated with mortality and with impairment of function and mobility. ${ }^{12}$ Application of the STS in different populations, such as those with neuro$\operatorname{logic}^{13}$ and orthopedic ${ }^{14,15}$ conditions, has been widely investigated. In contrast, only recent studies have explored the test in depth in the COPD population. ${ }^{16-19}$ Among the available information, it is known that the 5-repetition STS (5-rep STS) test is considered reliable and responsive, ${ }^{16}$ and the 1-min protocol (1-min STS) is a predictor of mortality in subjects with COPD. ${ }^{18}$

Many studies describe the relationship between the STS and commonly measured outcomes in subjects with COPD, such as exercise capacity, dyspnea, health-related questionnaires, and muscle strength, among others. ${ }^{16,20-24}$ However, these results were observed in a variety of protocols (ie, 5-rep STS, 30-s STS, and 1-min STS), ${ }^{25}$ and it is unknown which is the best protocol for assessing this population. Therefore, the primary objective of this study was to identify the best protocol according to the correlation of each of these tests with important clinical outcomes in subjects with COPD. We also aimed to compare and to verify the agreement of the protocols as well as whether they are able to predict functional exercise capacity and physical activity in daily life (PADL). The initial hypothesis was that there was a difference among the protocols, mainly between the 5-rep STS and the 1-min STS. Furthermore, we hypothesized that tests that lasted longer, such as the 1-min STS, could be more discriminative and would therefore be better correlated with functional capacity, muscle strength, maximal exercise capacity, health-related questionnaires, and PADL.

\section{Methods}

\section{Study Design}

This was a cross-sectional and observational study conducted from January 2014 to May 2015 at the Laboratory of Research in Respiratory Physiotherapy of the State Uni-

\section{QUICK LOOK}

\section{Current knowledge}

The sit-to-stand test (STS) is a simple and practical test aimed to evaluate functionality in patients with COPD. It is valid, reliable, and responsive, and it is also associated with many important clinical outcomes in this population. However, there are a variety of protocols available in the literature, and the best option to evaluate patients with COPD remains unknown.

\section{What this paper contributes to our knowledge}

Among different protocols of the STS test, the 1-min STS was the best to evaluate subjects with COPD because it was better associated with important clinical outcomes such as functional exercise capacity, functional status, and physical activity in daily life. The 5-rep and 1-min STS protocols were significantly different in terms of speed performance and physiologic demand; however, they were correlated and had a good level of agreement. All 3 STS protocols were able to identify subjects with low exercise capacity or preserved exercise capacity.

versity of Londrina in Brazil. All subjects with COPD underwent the following assessments: lung function, maximum and functional exercise capacity, peripheral muscle strength, PADL, and health-related quality-of-life and functional status questionnaires. Individuals also underwent 3 different protocols of the STS (5-rep STS, 30-s STS, and 1-min STS) in a randomized sequence. The study was approved by the ethics committee of the State University of Londrina, Brazil (080/2014), and all subjects signed a written informed consent.

\section{Participants}

A convenience sample was recruited through advertisements in media and health centers. The inclusion criteria of this study were subjects with a diagnosis of COPD according to the Global Initiative for Chronic Obstructive Lung Disease (GOLD) criteria, ${ }^{26}$ clinical stability (absence of exacerbations within the previous 3 months), and no participation in regular rehabilitation or physical exercise programs in the previous year.

Participants were excluded if they had any severe comorbidity that could impair performance in the tests, such as severe cardiovascular, orthopedic, or neuromuscular conditions, or if they, for any reason, did not complete all of the assessments. 


\section{Comparison of Sit-To-Stand Tests IN COPD}

\section{Sit-to-Stand Test Protocols}

Three protocols of STS (5-rep STS, 30-s STS, and 1-min STS) were chosen to make comparisons among tests. The reason for choosing these protocols is that they are the most commonly described in the literature for subjects with COPD. ${ }^{25}$ All 3 tests were performed in an armless chair with a height of $46 \mathrm{~cm}$; subjects were instructed to fold their arms across their chest and perform the stand up and sit down movement as quickly as possible. According to the protocol described by Jones et al, ${ }^{16}$ in the 5-rep test, subjects performed 5 movements of standing up and sitting down as quickly as they could, and a stopwatch was used to measure the time spent in the activity. In the 30-s and 1-min protocols, subjects were instructed to sit down and stand up as many times as possible within $30 \mathrm{~s}^{20}$ and $1 \mathrm{~min},{ }^{7}$ respectively, and the number of repetitions was recorded. Moreover, because the outcomes of these 3 protocols were different (time and number of repetitions), the speed (number of repetitions per s) was considered in the analysis. Heart rate, oxygen saturation $\left(\mathrm{S}_{\mathrm{pO}_{2}}\right)$, blood pressure, and symptoms of dyspnea and fatigue (rated with the modified Borg scale ${ }^{27}$ ) were measured before and after each test. The order of the tests was randomized for each subject, and the rest period between them was empirically standardized. After the 5-rep STS test, there was at least a 5-min interval for rest; after the 30-s STS protocol, at least $15 \mathrm{~min}$ of rest; and after the 1-min STS, at least $30 \mathrm{~min}$ of rest. Reference values for these 3 STS tests and the percentage of predicted time or repetitions were calculated for all of the protocols. ${ }^{9,28,29}$

\section{Assessments}

Lung function was assessed by spirometry using a portable spirometer (Spiropalm, COSMED, Italy). The test was performed according to the American Thoracic Society/European Respiratory Society (ATS/ERS) statement, ${ }^{30}$ and the predicted values were calculated using a specific equation for the Brazilian population. ${ }^{31}$

Maximum and functional exercise capacity were assessed with the incremental shuttle walking test (ISWT) and the 6MWT, respectively. The ISWT and the 6MWT were performed according to the ERS/ATS technical standard for field walking tests in chronic respiratory disease, ${ }^{5}$ and reference values for Brazilians were used for each test. ${ }^{32,33}$ Oxygen supplementation was provided when necessary. Subjects were separated into 2 groups according to the percentage of the predicted value for the distance walked in the 6MWT: those who covered $<82 \%$ of the predicted distance ${ }^{34}$ were classified as having low exercise capacity, and those above this threshold were considered to have preserved exercise capacity. Functional capacity was also evaluated with the 4-m gait speed (4MGS) test, in which subjects were instructed to walk at their own pace, with a self-selected speed, along a 4-m corridor. ${ }^{35}$ Two tests without rest were performed, and the fastest test was considered.

Quadriceps muscle strength was assessed by the 1-repetition maximum test with multi-gym equipment (CRW 1000; Embreex, Brusque, Brazil). The test was performed according to the Procedures Recommendations for Accurate Assessment of Muscular Strength and Power guideline. ${ }^{36}$

Two activity monitors assessed PADL: the DynaPort Activity Monitor (McRoberts BV, The Hague, The Netherlands) and the multisensor SenseWear Armband (BodyMedia, Pittsburgh, Pennsylvania). The main variables obtained by these devices were time spent in various activities: walking, standing, sitting, lying down, and locomotion per day (assessed with the DynaPort Activity Monitor); total energy expenditure; and time spent doing sedentary, moderate, intense, and very intense activities (assessed with the SenseWear Armband). Subjects were instructed to wear both devices for $7 \mathrm{~d}, 12 \mathrm{~h} / \mathrm{d}$, and the mean values from the $7 \mathrm{~d}$ were considered. For statistical analysis, subjects were separated into an active group and an inactive group according to the American College of Sports and Medicine (ACSM) recommendations. ${ }^{37}$ The active and inactive groups performed respectively above or below $30 \mathrm{~min} / \mathrm{d}$ of physical activity with at least moderate intensity. To classify moderate intensity of physical activity, the metabolic equivalents (METs) threshold was considered, according to ACSM standard (ie, 4.0-5.9 METs for subjects 40$64 \mathrm{y}$ old, 3.2-4.7 METs for subjects $>65 \mathrm{y}$ old). ${ }^{37}$

Health-related quality of life was assessed with the St George Respiratory Questionnaire, ${ }^{38}$ and self-reported functional status was assessed with the Pulmonary Functional Status and Dyspnea Questionnaire - modified version (PFSDQ-M). ${ }^{39}$

\section{Statistical Analyses}

All analyses were performed using the statistics software packages SPSS version 20.0 (SPSS, Chicago, Illinois), GraphPad Prism 6.0 (GraphPad Software, San Diego, California), and Medcalc version 15.8 (MedCalc Software, Ostend, Belgium). The normality of continuous variables was checked with the Shapiro-Wilk test and described as mean $\pm \mathrm{SD}$ or median (interquartile range). Correlations between the STS test and clinical outcomes were obtained using Pearson or Spearman correlation coefficients. Comparisons among the 3 STS protocols and variables measured before and after each test were analyzed by repeated measures analysis of variance or Friedman test followed by the Tukey or Dunn's post hoc tests, respectively. Likewise, the differences in heart rate, $\mathrm{S}_{\mathrm{pO}_{2}}$, blood pressure, and scores of dyspnea and fatigue before 


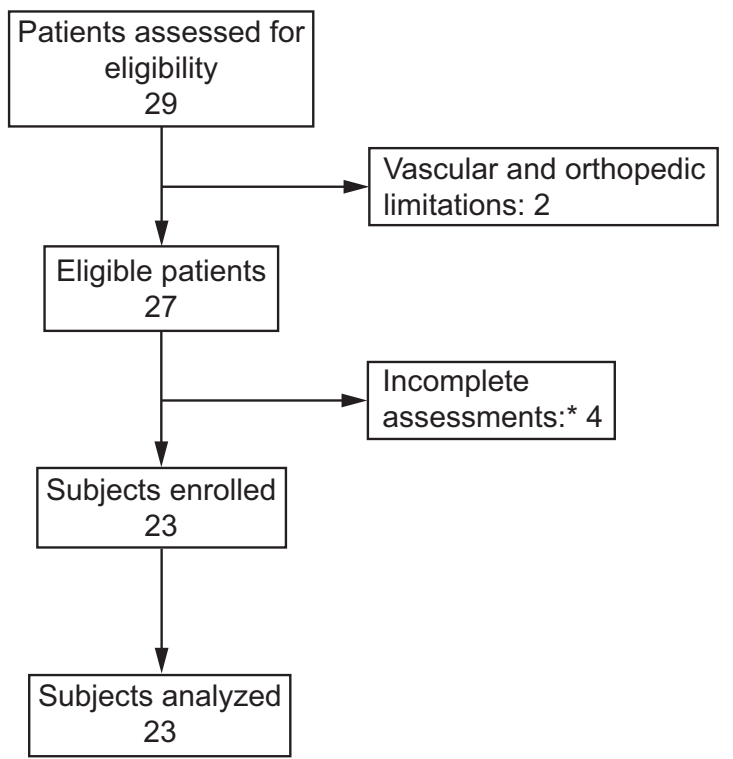

Fig. 1. Flow chart. *Reasons for incomplete assessments include exacerbation, personal reasons, and death.

and after each test were assessed with the Student $t$ test or Wilcoxon test. To analyze agreement between protocols, the intraclass correlation coefficient (ICC) and Bland-Altman plot were used. $.^{40} P \leq .05$ indicated statistical significance.

Receiver operating characteristic (ROC) curve analysis $^{41}$ was used to show the ability of each STS protocol to identify subjects with low or preserved functional exercise capacity on the 6MWT and as physically inactive or active in terms of PADL. The comparisons of areas under the ROC curve (AUC) were performed by the Hanley-McNeil method. ${ }^{42}$

Sample size calculation was performed with GPower 3.1.3 software (Franz Faul, Universitat Kiel, Germany), considering the study of Ozalevli et al. ${ }^{7}$ Taking into account a correlation between the 6MWT and the 1-min STS test of -0.75 , an alpha value of 0.01 , a power of $90 \%$, and $20 \%$ loss during the evaluation period, the number of subjects of a convenience sample for this study was 23 subjects.

\section{Results}

A total of 29 subjects with COPD took part in the study (Fig. 1), and 6 subjects were excluded before analysis; subject characteristics are described in Table $1 .{ }^{43}$ Overall, the majority of the sample was composed of subjects with a moderate degree of air flow obstruction and who were classified as GOLD II. Subjects walked a mean $\pm \mathrm{SD}$ distance of $476 \pm 63 \mathrm{~m}$ in the 6MWT, and 9 subjects (39\%) used oxygen supplementation during the test.
Table 1. Characteristics of Subjects With COPD

\begin{tabular}{|c|c|}
\hline Gender, $n$ (male/female) & $11 / 12$ \\
\hline Age, y & $68 \pm 8$ \\
\hline Body mass index, $\mathrm{kg} / \mathrm{m}^{2}$ & $26 \pm 5$ \\
\hline $\mathrm{VEF}_{1}, \mathrm{~L}$ & $1.31 \pm 0.43$ \\
\hline $\mathrm{VEF}_{1}, \%$ predicted & $53 \pm 15$ \\
\hline $\mathrm{FEV}_{1} / \mathrm{FVC}, \%$ & $55 \pm 11$ \\
\hline GOLD II/III/IV & $16 / 6 / 1$ \\
\hline 5-rep STS, s & $10 \pm 3$ \\
\hline 5-rep STS predicted, s & $12.12 \pm 0.61$ \\
\hline 5-rep STS \% predicted, s & $84 \pm 24$ \\
\hline 30-s STS, repetitions & $14 \pm 3$ \\
\hline 30-s STS predicted, s & $16 \pm 1$ \\
\hline 30-s STS \% predicted, s & $89 \pm 27$ \\
\hline 1-min STS, repetitions & $27 \pm 6$ \\
\hline 1-min STS predicted, repetitions & $32 \pm 3$ \\
\hline 1-min STS \% predicted, repetition) & $85 \pm 23$ \\
\hline 6MWD, m & $476 \pm 63$ \\
\hline $6 \mathrm{MWT}, \%$ predicted & $90 \pm 14$ \\
\hline ISWT, m & $448 \pm 102$ \\
\hline ISWT, \% predicted & $77 \pm 26$ \\
\hline 1-RM quadriceps, $\mathrm{k}$ & $16 \pm 7$ \\
\hline 4-MGS test, $\mathrm{m} / \mathrm{s}$ & $1.42 \pm 0.27$ \\
\hline SGRQ total score & $38(22-42)$ \\
\hline PFSDQ-M dyspnea score & $6(2-13)$ \\
\hline PFSDQ-M fatigue score & $5(0.75-10)$ \\
\hline PFSDQ-M activity score & $5(0.75-9)$ \\
\hline PAL index & $1.47 \pm 0.11$ \\
\hline TEE, kcal & $2029 \pm 395$ \\
\hline PAD $>$ moderate intensity, min & $48(18-138)$ \\
\hline $\begin{array}{l}\text { Data expressed as absolute frequency, mean } \pm \mathrm{S} \\
N=23 \\
\text { GOLD }=\text { Global Initiative for Chronic Lung Dis } \\
\text { 5-rep STS }=5 \text {-repetition sit-to-stand test } \\
\text { 30-s STS }=30 \text {-s sit-to-stand test } \\
\text { 1-min STS }=1 \text {-min sit-to-stand test } \\
6 \mathrm{MWD}=6 \text {-min walk distance } \\
\text { 6MWT = 6-min walk test } \\
\text { ISWT = incremental shuttle walking test } \\
\text { 1-RM = 1-repetition maximum } \\
\text { 4MGS = 4-m gait speed } \\
\text { SGRQ = St George's Respiratory Questionnaire } \\
\text { PFSDQ-M = Modified Pulmonary Functional St } \\
\text { PAL = physical activity level index } \\
\text { TEE = total energy expenditure } \\
\text { PAD = physical activity duration }\end{array}$ & le range [IQR]). \\
\hline
\end{tabular}

\section{Association of STS Protocols With Clinical Outcomes}

Table 2 presents the correlations found between the 3 protocols of the STS and clinical outcomes such as functional exercise capacity, functional status, and PADL. A significant association was found between the 5-rep STS and functional capacity evaluated by the 4MGS. The 30-s STS protocol was also correlated with the 4MGS. Some variables of PADL measured with the DynaPort Activity Monitor, such as walking and locomotion, were also associated with this protocol (Table 2). 
Table 2. Correlations Between STS Protocols and Clinical Variables in Subjects With COPD

\begin{tabular}{|c|c|c|c|c|c|c|}
\hline & \multicolumn{2}{|c|}{$\begin{array}{c}\text { 5-rep } \\
\text { STS (rep/s) }\end{array}$} & \multicolumn{2}{|c|}{$\begin{array}{c}30-\mathrm{s} \\
\mathrm{STS}(\mathrm{rep} / \mathrm{s})\end{array}$} & \multicolumn{2}{|c|}{$\begin{array}{c}1-\min \\
\text { STS (rep/s) }\end{array}$} \\
\hline & $\mathrm{r}$ & $P$ & $\mathrm{r}$ & $P$ & $\mathrm{r}$ & $P$ \\
\hline 5-rep STS (rep/s) & NA & NA & 0.71 & $<.001$ & 0.71 & $<.001$ \\
\hline 30-s STS (rep/s) & 0.71 & $<.001$ & NA & NA & 0.68 & $<.001$ \\
\hline 1-min STS (rep/s) & 0.71 & $<.001$ & 0.68 & $<.001$ & NA & NA \\
\hline 4MGS test $(\mathrm{m} / \mathrm{s})$ & 0.54 & .009 & 0.52 & .01 & 0.64 & .001 \\
\hline PFSDQ-M activity score & 0.38 & .08 & 0.04 & .85 & 0.43 & .043 \\
\hline Walking (min) & 0.19 & .37 & 0.46 & .02 & 0.40 & .054 \\
\hline Standing $(\min )$ & 0.35 & .10 & 0.17 & .42 & 0.49 & .01 \\
\hline Locomotion (min) & 0.37 & .08 & 0.48 & .02 & 0.52 & .01 \\
\hline \multicolumn{7}{|c|}{$\begin{array}{l}\mathrm{r}=\text { Pearson or Spearman correlation coefficient value } \\
\text { 5-rep STS = 5-repetition sit-to-stand test } \\
\text { 30-s STS }=30 \text {-s sit-to-stand test } \\
\text { 1-min STS = 1-min sit-to-stand test } \\
\text { 4MGS = 4-m gait speed } \\
\text { PFSDQ-M = Modified Pulmonary Functional Status and Dyspnea Questionnaire } \\
\text { NA = not applicable }\end{array}$} \\
\hline
\end{tabular}

Many other variables, such as the 6MWT $(\mathrm{r}=0.40$, $P=.058)$, the activity score of the PFSDQ-M questionnaire, physical activity duration, and standing position were associated with the 1-min STS, as well as the 4MGS, walking, and locomotion variables. The values of correlation of this protocol and the 4MGS and PADL outcomes were higher than for the other 2 STS tests (Table 2).

None of the other assessed outcomes, such as lung function $(P=.90$ for 5-rep STS; $P=.65$ for the 30-s STS; $P=.38$ for the 1 -min STS), ISWT ( $P=.39$ for 5 -rep STS; $P=.13$ for the $30-\mathrm{s} \mathrm{STS} ; P=.26$ for the 1 -min STS), St George Respiratory Questionnaire ( $P=.20$ for 5-rep STS; $P=.29$ for the 30 -s STS; $P=.09$ for the 1-min STS), and quadriceps strength $(P=.93$ for 5 -rep STS; $P=.86$ for the 30 -s STS; $P=.53$ for the 1-min STS) were associated with the 5-rep STS, 30-s STS, or 1-min STS protocols.

\section{Comparisons Among Protocols}

The mean \pm SD speeds (repetitions [rep]/s) of the 3 STS protocols differed (5-rep STS $0.53 \pm 0.16 \mathrm{rep} / \mathrm{s}, 30$-s STS $0.48 \pm 0.13 \mathrm{rep} / \mathrm{s}, 1-\mathrm{min}$ STS $0.45 \pm 0.11 \mathrm{rep} / \mathrm{s}, P=.01$ ) (Fig. 2). Post hoc analysis showed a difference between the 5-rep STS and 1-min STS, meaning that subjects performed the 5-rep STS protocol faster than the 1-min STS $(P=.01)$.

Subjects started all of the tests with similar $\mathrm{S}_{\mathrm{pO}_{2}}(P=$ $.29)$, heart rate $(P=.39)$, and systolic $(P=.28)$ and diastolic blood pressure $(P=.96)$. Moreover, there were no differences in the symptoms of dyspnea $(P=.09)$ and fatigue $(P=.31)$ measured before each protocol.

The comparisons of the changes in oxygen saturation, hemodynamic responses, and symptoms' variables, de-

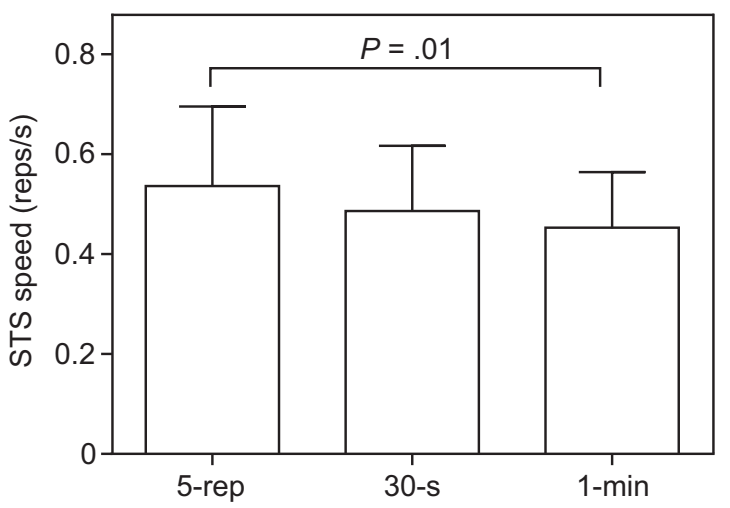

Fig. 2. Comparison of the speed among the 5-rep, 30-s, and 1-min protocols of the sit-to-stand (STS) test.

scribed in Table 3, differed among the protocols except for the diastolic blood pressure. In the 1-min STS protocol, subjects presented higher oxygen desaturation, increased heart rate, and symptoms of fatigue compared to the 5-rep STS and the 30-s STS. Similarly, in the comparison of the 5-rep STS and 30-s STS, the latter showed a greater increase in heart rate, systolic blood pressure, and dyspnea (Table 3).

In addition to this analysis, Table 4 shows the differences between oxygen saturation and the hemodynamic and symptom variables measured before and after each protocol. In the 5-rep STS, the final heart rate, systolic blood pressure, and symptoms of dyspnea were higher than at the beginning of the test. The 30-s STS and 1-min STS protocols showed significant desaturation and increases in heart rate, systolic blood pressure, and symptoms of dyspnea and fatigue. The diastolic blood pressure 
Table 3. Comparison of the Changes in Observed in Each of the STS Protocols

\begin{tabular}{|c|c|c|c|c|}
\hline & 5-rep STS & 30-s STS & 1-min STS & $P$ \\
\hline$\Delta \mathrm{S}_{\mathrm{pO}_{2}}, \%$ & $-1 \pm 2$ & $-1 \pm 2$ & $-3 \pm 4 * \dagger$ & .004 \\
\hline$\Delta$ Heart rate, beats $/ \mathrm{min}$ & $7 \pm 7 \dagger$ & $16 \pm 10^{*}$ & $22 \pm 13 * \dagger$ & $<.001$ \\
\hline$\Delta$ Systolic blood pressure, $\mathrm{mm} \mathrm{Hg}$ & $0(0-10) \dagger$ & $20(0-30)^{*}$ & $30(10-40)^{*}$ & $<.001$ \\
\hline$\Delta$ Diastolic blood pressure, $\mathrm{mm} \mathrm{Hg}$ & $0(0-10)$ & $0(0-0)$ & $0(0-10)$ & NS \\
\hline$\Delta$ Dyspnea score (Borg scale) & $0(0-0.5) \dagger$ & $1(0.5-2)^{*}$ & $2.5(1-3)^{*}$ & $<.001$ \\
\hline$\Delta$ Fatigue score (Borg scale) & $0(0-0.5)$ & $0.5(0-2)$ & $2(1-3)^{* \dagger}$ & $<.001$ \\
\hline
\end{tabular}

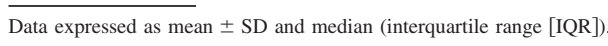

$* P \leq .05$ versus 5 -rep- STS

$\dagger P \leq .05$ versus 30 -s STS.

5-rep STS $=5$-repetition sit-to-stand test

30-s STS $=30$-s sit-to-stand test

1 -min STS $=1$-min sit-to-stand test

$\mathrm{NS}=$ not significant

Table 4. Comparison of Variables Measured Before and After Each STS Protocol

\begin{tabular}{|c|c|c|c|c|c|c|c|c|c|}
\hline & \multicolumn{3}{|c|}{ 5-rep STS } & \multicolumn{3}{|c|}{ 30-s STS } & \multicolumn{3}{|c|}{ 1-min STS } \\
\hline & Before & After & $P$ & Before & After & $P$ & Before & After & $P$ \\
\hline $\mathrm{S}_{\mathrm{pO}_{2}}(\%)$ & $95 \pm 3$ & $94 \pm 2$ & .12 & $95 \pm 2$ & $94 \pm 3$ & .01 & $95 \pm 2$ & $91 \pm 5$ & $<.001$ \\
\hline Heart rate, beats/min & $87 \pm 13$ & $95 \pm 13$ & $<.001$ & $86 \pm 12$ & $102 \pm 13$ & $<.001$ & $86 \pm 12$ & $109 \pm 17$ & $<.001$ \\
\hline $\begin{array}{l}\text { Systolic blood pressure, } \\
\text { mm Hg }\end{array}$ & $120(110-140)$ & $130(120-140)$ & .003 & $120(110-130)$ & $140(130-150)$ & $<.001$ & $130(120-140)$ & $150(140-180)$ & $<.001$ \\
\hline $\begin{array}{l}\text { Diastolic blood pressure, } \\
\mathrm{mm} \mathrm{Hg}\end{array}$ & $80(70-90)$ & $90(80-90)$ & .11 & $80(70-90)$ & $80(70-90)$ & .88 & $80(80-90)$ & $90(80-100)$ & .007 \\
\hline Dyspnea score (Borg scale) & $0(0-1)$ & $0(0-2)$ & .031 & $0(0-1)$ & $2(1-3)$ & $<.001$ & $0.5(0-2)$ & $3(2-5)$ & $<.001$ \\
\hline Fatigue score (Borg scale) & $0(0-2)$ & $0(0-2)$ & .24 & $0(0-0.5)$ & $1(0-3)$ & $<.001$ & $0(0-0.5)$ & $2(1-5)$ & $<.001$ \\
\hline \multicolumn{10}{|c|}{$\begin{array}{l}\text { Data expressed as mean } \pm \mathrm{SD} \text { and median (interquartile range }[\mathrm{IQR}] \text { ). } \\
\text { 5-rep STS }=5 \text {-repetition sit-to-stand test } \\
\text { 30-s STS }=30 \text {-s sit-to-stand test } \\
\text { 1-min STS }=1 \text {-min sit-to-stand test }\end{array}$} \\
\hline
\end{tabular}

significantly increased in the 1-min STS and did not present changes in the 30-s STS protocol.

\section{Correlation and Agreement Among Protocols}

The 5-rep STS, 30-s STS, and 1-min STS tests had a significant correlation with each other, with $r$ values $>0.68$ (Table 2). These protocols also showed a good agreement pairwise (ICC for 5-rep STS and 30-s STS $=0.85$ [95\% CI 0.61- 0.93, $P<.001$ ]; ICC for 5-rep STS and 1-min STS $=$ 0.73 [95\% CI $0.22-0.89, P<.001$ ]; ICC for 30 -s STS and 1 -min STS $=0.77$ [95\% CI 0.46-0.90, $P<.001]$ ), illustrated by the Bland-Altman plot (Fig. 3).

\section{Sit-to-Stand Test to Predict Functional Exercise Capacity and PADL}

Concerning functional exercise capacity assessed by the 6MWT, $15(65 \%)$ subjects were considered to have pre- served capacity, and 8 subjects (35\%) had a predicted distance $<82 \%$. The AUC calculated for the 3 protocols had discriminative values for poor and preserved exercise capacity: 5-rep STS 0.71 [95\% CI 0.48-0.93], 30-s STS 0.85 [95\% CI 0.70-0.10], and 1-min STS 0.82 [95\% CI 0.64-1.0]. Subsequently, the comparison of AUCs (Fig. 4) did not present any difference (difference between areas: 5-rep STS vs 30-s STS $=0.14, P=.11 ; 5$-rep STS vs $1-\min \mathrm{STS}=0.11, P=.13 ; 30-\mathrm{s}$ STS vs $1-\min \mathrm{STS}=$ $0.02, P=.73$ ).

Analysis regarding PADL showed that 11 (48\%) subjects were classified as active and $12(52 \%)$ as inactive. The 5-rep STS had an AUC of 0.65 [95\% CI 0.42-0.87], the 30-s STS had an AUC of 0.65 [95\% CI 0.41-0.87], and the 1-min STS had an AUC of 0.57 [95\% CI 0.320.83 ], which did not allow distinguishing between active and inactive subjects. There were no differences between these AUCs (Fig. 4), and the values of the differences between areas were 0.02 for the 5-rep STS versus 30-s 


\section{COMPARISOn OF Sit-TO-STANd Tests IN COPD}
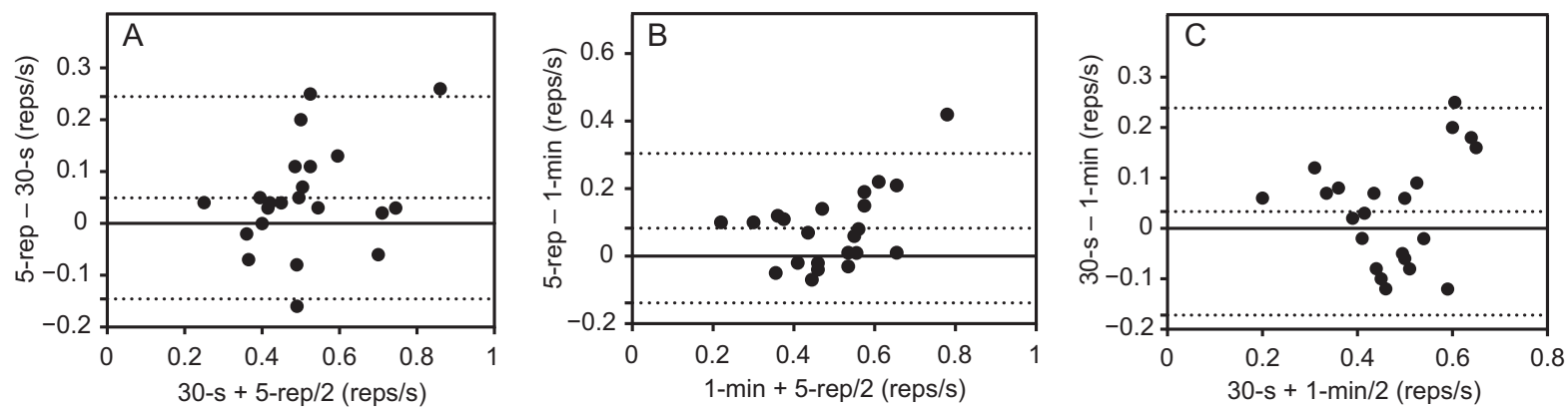

Fig. 3. Bland-Altman plots of the difference between STS test protocols plotted against the mean value of the STS test: 5-rep vs 30-s (A); 5-rep vs 1-min (B) and 30-s vs 1-min (C). Outside dotted lines indicate the upper and lower limits of agreement, and center dotted lines show mean value. Intraclass correlation coefficient $P<.001$ for all. STS $=$ sit-to-stand.
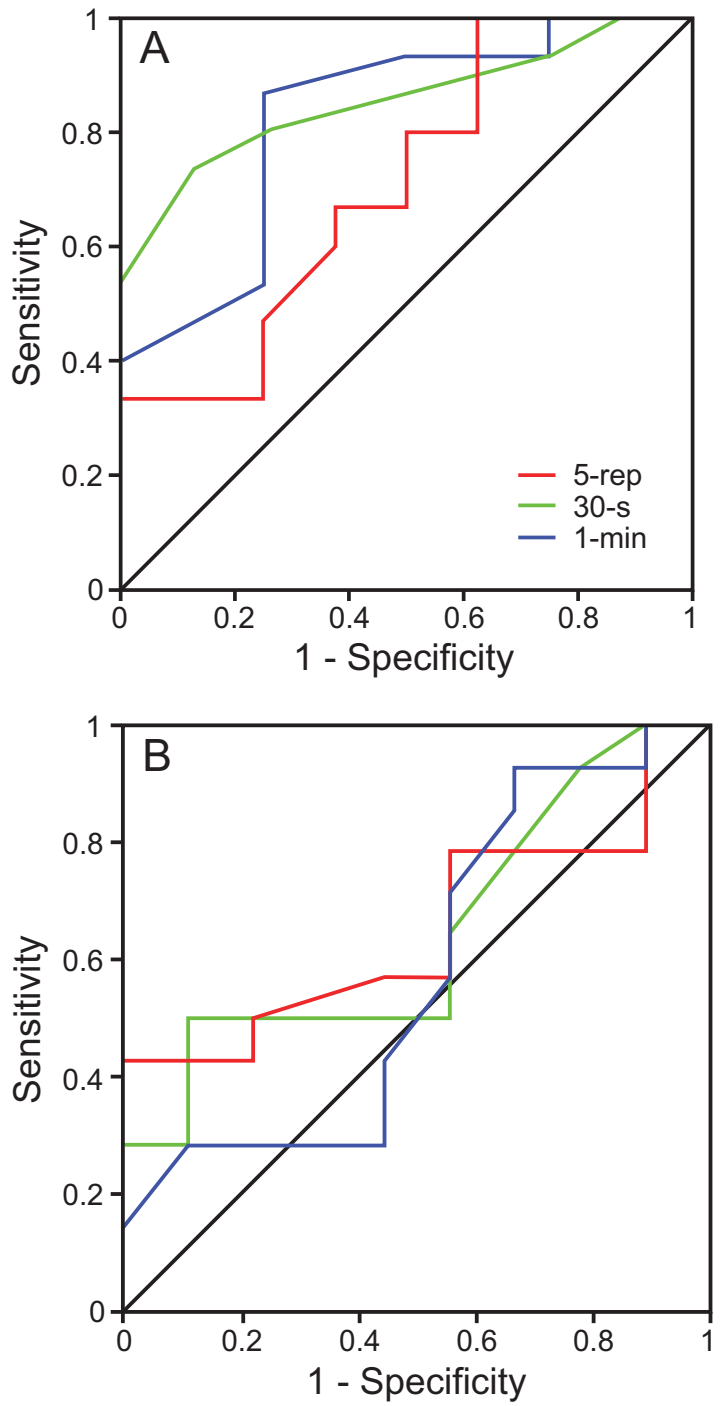

Fig. 4. Comparison among the areas under the curve of the 5-rep, $30-\mathrm{s}$, and 1-min STS test protocols in subjects with (A) low exercise capacity or preserved exercise capacity in the 6-min walk test and in subjects classified as (B) active or inactive regarding physical activities of daily living. STS = sit-to-stand.
STS $(P=.79), 0.10$ for the 5-rep STS versus 1-min STS $(P=.22)$, and 0.08 for the 30 -s STS versus 1-min STS $(P=.42)$.

\section{Discussion}

This research studied which STS protocol (5-rep STS, 30-s STS, and 1-min STS) had the strongest correlation with important clinical outcomes in subjects with COPD. All 3 protocols exhibited associations with functional capacity measured by the 4MGS. The 30-s STS protocol correlated with PADL, and the 1-min STS showed association with the 6MWT, the PFSDQ-M questionnaire, and PADL. There was a difference between the 5-rep STS and the 1-min STS protocol, in that subjects stood up and sat down faster in the 5-rep STS than in the 1-min STS protocol. The comparison among changes in oxygen saturation and cardiovascular and symptom variables revealed that the 1-min STS was more stressful, with the exception of diastolic blood pressure. Furthermore, there was more desaturation and heart rate, systolic and diastolic blood pressure, and symptoms of dyspnea and fatigue were increased at the end of the 1-min STS test. Despite these differences, the 3 protocols correlated well with each other and had good agreement. Moreover, the 3 protocols were able to identify subjects with low exercise capacity and preserved exercise capacity in the 6MWT with AUC $>0.71$; however, this was not the case for PADL because none of the protocols were able to adequately predict subjects classified as active or inactive.

The STS test was first described by Csuka and McCarty, ${ }^{44}$ in which a protocol of 10 repetitions was used. It was considered an inexpensive, simple, rapid, and reproducible test to assess lower limb muscle strength in healthy subjects. After this study, many other protocols of the STS were used to test functional capacity of the lower limbs in a variety of populations, including subjects with COPD. A large number of protocols are available, and this study is the first to show the best correlation of these tests with 
clinical outcomes in COPD as well as the differences among the tests in this population.

All 3 protocols were associated with the 4MGS, which is also considered a functional test. ${ }^{25}$ This result was expected because both tests assess lower limb function with usually adopted movements in daily life. Ozalevli et al showed that the STS correlated with the score of daily walking activities of the Nottingham Health Profile Survey questionnaire in subjects with COPD. ${ }^{7}$ Likewise, Whitney et al verified a moderate correlation between the 5-rep STS and gait analysis in subjects with balance disorders. ${ }^{45}$ Another important correlation we found was between PADL and the 30-min STS protocol, as well as with the 1-min STS protocol. However, the 1-min STS had a better association with PADL in COPD compared to the 30-s STS protocol. Similar results of a correlation between STS and PADL were found by van Gestel et $a l,{ }^{24}$ who showed a correlation between the 1-min STS protocol and objectively measured physical activity. ${ }^{24}$ Indeed, this association could be explained because motion sensor devices (ie, accelerometers) are valid for measuring STS movement duration in the elderly. ${ }^{46,47}$ Only the 1-min STS correlated with other variables such as the 6MWT and the activity score of the PFSDQ-M questionnaire. There is some evidence in the literature suggesting the STS as an alternative to the 6MWT for measuring functional capacity. ${ }^{7,8}$ Both tests have a good correlation, and the advantage of the STS is that it causes less hemodynamic stress for patients with COPD than the 6MWT. ${ }^{7}$ Moreover, the functional status obtained by the PFSDQ-M questionnaire was significantly associated with the 1-min STS test. This correlation probably occurred because both tools are used to evaluate function in subjects with COPD. ${ }^{48}$

In this study, we verified a difference among protocols. Subjects completed the 5-rep STS faster than the 1-min STS. This fact might have occurred due to an increase of symptoms during the 1-min STS test compared to the 5-rep STS protocol (Table 3), resulting in lower performance. Similar results have been demonstrated in the gait speed test, in which healthy elderly had a higher value of speed for shorter distances (comparison of $5 \mathrm{~m}$ and $10 \mathrm{~m}$ ). ${ }^{49}$ Moreover, the 1-min STS test presented higher oxygen desaturation and higher hemodynamic and symptom demands in comparison to the other 2 tests (Tables 3 and 4). It is reasonable that the longest test (1-min STS) demanded higher physical effort. Despite this difference, the 3 STS protocols had a moderate association $(r \geq 0.68)$ and good agreement (ICC $\geq 0.73$ ) among them.

Lower limb strength is a meaningful factor that could potentially limit an elderly person's ability to stand up and sit down from a chair. ${ }^{51}$ Even though many studies in the literature have shown a correlation between the STS and quadriceps muscle strength, both in healthy subjects ${ }^{51-56}$ and in subjects with COPD, ${ }^{16,20-23}$ in this study we did not find any correlation between these variables. One plausible explanation for this could be related to the limitation of the assessment method for muscle force used in our study (ie, the 1-repetition maximum test). The use of a more accurate tool to assess muscle strength, such as dynamometry, may have led to different findings. The absence of an association between STS and quadriceps muscle strength could also be explained by the requirement of other abilities in daily life rather than muscle force, such as postural and balance control ${ }^{17,45}$ and hip and ankle motion. ${ }^{55}$

In a discriminative analysis, subjects with COPD with low or preserved exercise capacity according to the 6MWT were adequately identified by the proposed STS protocols. All 3 tests showed a similar AUC, meaning that they have similarity in predicting exercise capacity. Similar results were found in the study by Jones et al, in which the STS was considered a stratification tool to identify impaired walking capacity obtained by the ISWT (AUC $=0.82) .{ }^{16}$ Moreover, a recent study showed that the 5-rep STS is a clinical determinant of poor exercise capacity in the 6MWT. ${ }^{57}$ On the other hand, none of these tests was able to predict active or inactive subjects. This finding resembles the study of van Gestel et al, in which the STS was not able to predict inactive lifestyle in subjects with COPD $($ AUC $=0.31) .{ }^{24}$ This result was expected because there was no correlation between the STS and the physical activity duration variable in this study. In addition, considering the STS as a functional capacity test, Pitta et al showed that tests such as the 6MWT might predict activities in daily life better than single variables of physical functioning. ${ }^{58}$

Although many STS protocols are available in the literature, choosing 1 of the 3 most broadly used in patients with COPD is important to evaluate lower limb function. Hence, this study suggests that the 1-min STS protocol could be better for evaluating functional capacity in this population because it had better correlations with important clinical outcomes. While the time spent performing the 1-min STS protocol is longer than the other 2 protocols, it still remains a quick, practical, and useful test in clinical settings.

\section{Limitations}

First, although it is known that chair height can influence the performance of the STS, ${ }^{59-61}$ this study could not ensure that subjects were positioned to have exactly $90^{\circ}$ of hip and knee flexion in the chair. However, we standardized the chair height $(46 \mathrm{~cm})$ by using the same chair for all subjects, similar to the majority of previous studies. ${ }^{16,18,22}$ We believe this limitation did not negatively affect the study results because in daily life chair height is standardized for the overall population, and it is not usually possible to adjust chairs individually. ${ }^{25}$ 


\section{Comparison of Sit-To-Stand Tests in COPD}

Second, the 3 protocols of the STS were performed in a randomized sequence, and the resting time after each test was empirically determined. Even though this study did not analyze this recovery time in depth, this period between the tests appeared to be adequate because there were no differences among $\mathrm{S}_{\mathrm{pO}_{2}}$, heart rate, systolic and diastolic blood pressure, and symptoms of dyspnea and fatigue recorded before each test.

Finally, there was no subject classified as GOLD I in our sample. The lack of subjects classified in the mild stage of COPD and the average $\mathrm{FEV}_{1}$ restricts these results to subjects with moderate to severe degrees of air flow obstruction.

\section{Conclusions}

In summary, the 1-min STS seems to be the best protocol to evaluate subjects with COPD because it was better associated with important clinical outcomes such as functional exercise capacity, functional status, and PADL. It also generated higher hemodynamic demands than the other studied tests. The 5-rep STS and 1-min STS protocols were significantly different in terms of speed performance and physiological demands; however, they were correlated and had a good level of agreement. Furthermore, all 3 protocols were able to identify subjects with low exercise capacity or preserved exercise capacity, although none of the protocols could classify subjects as active or inactive in daily life.

\section{ACKNOWLEDGMENTS}

We are grateful to our colleagues at the Laboratory of Research in Respiratory Physiotherapy of State University of Londrina Brazil and CAPES for their contributions to this study.

\section{REFERENCES}

1. Couillard A, Muir JF, Veale D. COPD recent findings: impact on clinical practice. COPD 2010;7(3):204-213.

2. Eisner MD, Iribarren C, Blanc PD, Yelin EH, Ackerson L, Byl N, et al. Development of disability in chronic obstructive pulmonary disease: beyond lung function. Thorax 2011;66(2):108-114.

3. Eisner MD, Blanc PD, Yelin EH, Sidney S, Katz PP, Ackerson L, et al. COPD as a systemic disease: impact on physical functional limitations. Am J Med 2008;121(9):789-796.

4. Downs CA. Functional assessment of chronic obstructive pulmonary disease. J Am Acad Nurse Pract 2011;23(4):161-167.

5. Holland AE, Spruit MA, Troosters T, Puhan MA, Pepin V, Saey D, et al. An official European Respiratory Society/American Thoracic Society technical standard: field walking tests in chronic respiratory disease. Eur Respir J 2014;44(6):1428-1446.

6. Kocks JW, Asijee GM, Tsiligianni IG, Kerstjens HA, van der Molen T. Functional status measurement in COPD: a review of available methods and their feasibility in primary care. Prim Care Respir J 2011;20(3):269-275.

7. Ozalevli S, Ozden A, Itil O, Akkoclu A. Comparison of the sit-tostand test with 6-min walk test in patients with chronic obstructive pulmonary disease. Respir Med 2007;101(2):286-293.
8. Aguilaniu B, Roth H, Gonzalez-Bermejo J, Jondot M, Maitre J, Denis F, et al. A simple semipaced 3-minute chair rise test for routine exercise tolerance testing in COPD. Int J COPD 2014;9: 1009-1019.

9. Bohannon RW. Reference values for the five-repetition sit-to-stand test: a descriptive meta-analysis of data from elders. Percept Mot Skills 2006;103(1):215-222.

10. Zhang F, Ferrucci L, Culham E, Metter EJ, Guralnik J, Deshpande $\mathrm{N}$. Performance on five times sit-to-stand task as a predictor of subsequent falls and disability in older persons. J Aging Health 2013;25(3):478-492.

11. Millor N, Lecumberri P, Gomez M, Martinez-Ramirez A, Izquierdo M. An evaluation of the 30-s chair stand test in older adults: frailty detection based on kinematic parameters from a single inertial unit. J Neuroeng Rehabil 2013;10:86.

12. Janssen WG, Bussmann HB, Stam HJ. Determinants of the sit-tostand movement: a review. Phys Ther 2002;82(9):866-879.

13. Silva PF, Quintino LF, Franco J, Faria CD. Measurement properties and feasibility of clinical tests to assess sit-to-stand/stand-to-sit tasks in subjects with neurological disease: A systematic review. Braz J Phys Ther 2014;18(2):99-110.

14. Abujaber SB, Marmon AR, Pozzi F, Rubano JJ, Zeni JA, Jr. Sit-tostand biomechanics before and after total hip arthroplasty. J Arthroplasty 2015;30(11):2017-2033.

15. Bouchouras G, Patsika G, Hatzitaki V, Kellis E. Kinematics and knee muscle activation during sit-to-stand movement in women with knee osteoarthritis. Clin Biomech 2015;30(6):599-607.

16. Jones SE, Kon SS, Canavan JL, Patel MS, Clark AL, Nolan CM, et al. The five-repetition sit-to-stand test as a functional outcome measure in COPD. Thorax 2013;68(11):1015-1020.

17. Janssens L, Brumagne S, McConnell AK, Claeys K, Pijnenburg M, Goossens N, et al. Impaired postural control reduces sit-to-stand-tosit performance in individuals with chronic obstructive pulmonary disease. PLoS One 2014;9(2):e88247.

18. Puhan MA, Siebeling L, Zoller M, Muggensturm P, ter Riet G. Simple functional performance tests and mortality in COPD. Eur Respir J 2013;42(4):956-963.

19. Pessoa BV, Jamami M, Basso RP, Regueiro EMG, Di Lorenzo VAP, Costa D. Teste do degrau e teste da cadeira: comportamento das respostas metábolo-ventilatórias e cardiovasculares na DPOC. Fisioterapia em Movimento 2012;25:105-115.

20. Benton MJ, Alexander JL. Validation of functional fitness tests as surrogates for strength measurement in frail, older adults with chronic obstructive pulmonary disease. Am J Phys Med Rehabil 2009;88(7): 579-583.

21. Butcher SJ, Pikaluk BJ, Chura RL, Walkner MJ, Farthing JP, Marciniuk DD. Associations between isokinetic muscle strength, highlevel functional performance, and physiological parameters in patients with chronic obstructive pulmonary disease. Int J COPD 2012; 7:537-542.

22. Rausch-Osthoff AK, Kohler M, Sievi NA, Clarenbach CF, van Gestel AJ. Association between peripheral muscle strength, exercise performance, and physical activity in daily life in patients with chronic obstructive pulmonary disease. Multidiscip Respir Med 2014;9(1):37.

23. Roig M, Eng JJ, MacIntyre DL, Road JD, Reid WD. Deficits in muscle strength, mass, quality, and mobility in people with chronic obstructive pulmonary disease. J Cardiopulm Rehabil Prev 2011; 31(2):120-124.

24. van Gestel AJ, Clarenbach CF, Stowhas AC, Rossi VA, Sievi NA, Camen G, et al. Predicting daily physical activity in patients with chronic obstructive pulmonary disease. PLoS One 2012;7(11): e48081. 


\section{Comparison of Sit-To-Stand Tests In COPD}

25. Bisca GW, Morita AA, Hernandes NA, Probst VS, Pitta F. Simple lower limb functional tests in patients with chronic obstructive pulmonary disease: a systematic review. Arch Phys Med Rehabil 2015; 96(12):2221-2230.

26. Global Initiative for Chronic Obstructive Pulmonary Disease. Global strategy for the diagnosis, management and prevention for chronic obstructive pulmonary disease. http://goldcopd.org/. Accessed April 4, 2018.

27. Mahler DA, Wells CK. Evaluation of clinical methods for rating dyspnea. Chest 1988;93(3):580-586.

28. Rikli RE, Jones CJ. Development and validation of criterion-referenced clinically relevant fitness standards for maintaining physical independence in later years. Gerontologist 2013;53(2):255-267.

29. Strassmann A, Steurer-Stey C, Lana KD, Zoller M, Turk AJ, Suter $\mathrm{P}$, et al. Population-based reference values for the 1-min sit-to-stand test. Int J Public Health 2013;58(6):949-953.

30. Miller MR, Hankinson J, Brusasco V, Burgos F, Casaburi R, Coates A, et al. Standardisation of spirometry. Eur Respir J 2005;26(2):319338.

31. Pereira CA, Sato T, Rodrigues SC. New reference values for forced spirometry in white adults in Brazil. J Bras Pneumol 2007;33(4): 397-406.

32. Probst VS, Hernandes NA, Teixeira DC, Felcar JM, Mesquita RB, Goncalves CG, et al. Reference values for the incremental shuttle walking test. Respir Med 2012;106(2):243-248.

33. Britto RR, Probst VS, de Andrade AF, Samora GA, Hernandes NA, Marinho PE, et al. Reference equations for the six-minute walk distance based on a Brazilian multicenter study. Braz J Phys Ther 2013;17(6):556-563.

34. Troosters T, Gosselink R, Decramer M. Six minute walking distance in healthy elderly subjects. Eur Respir J 1999;14(2):270-274.

35. Kon SS, Patel MS, Canavan JL, Clark AL, Jones SE, Nolan CM, et al. Reliability and validity of 4-metre gait speed in COPD. Eur Respir J 2013;42(2):333-340.

36. Lee EB, Weir JP. Procedures recommendation I: accurate assessment of muscular strength and power. J Exercise Physiol 2001;4(3): $1-21$.

37. Garber CE, Blissmer B, Deschenes MR, Franklin BA, Lamonte MJ, Lee IM, et al. American College of Sports Medicine position stand. Quantity and quality of exercise for developing and maintaining cardiorespiratory, musculoskeletal, and neuromotor fitness in apparently healthy adults: guidance for prescribing exercise. Med Sci Sports Exerc 2011;43(7):1334-1359.

38. Sousa TCd, Jardim JR, Jones P. Validation of the Saint George's Respiratory Questionnaire in patients with chronic obstructive pulmonary disease in Brazil. J Pneumol 2000;26(3):119-128.

39. Kovelis D, Segretti NO, Probst VS, Lareau SC, Brunetto AF, Pitta F. Validation of the Modified Pulmonary Functional Status and Dyspnea Questionnaire and the Medical Research Council scale for use in Brazilian patients with chronic obstructive pulmonary disease. J Bras Pneumol 2008;34(12):1008-1018.

40. Bland JM, Altman DG. Statistical methods for assessing agreement between two methods of clinical measurement. Lancet 1986;1(8476): 307-310.

41. Hanley JA, McNeil BJ. The meaning and use of the area under a receiver operating characterist (ROC) curve. Radiology 1982;143(1): 29-36.

42. Hanley JA, McNeil BJ. A method of comparing the areas under receiver operating characteristic curves derived from the same cases. Radiology 1983;148(3):839-843.

43. von Elm E, Altman DG, Egger M, Pocock SJ, Gotzsche PC, Vandenbroucke JP. The Strengthening the Reporting of Observational Studies in Epidemiology (STROBE) statement: guidelines for reporting observational studies. Lancet 2007;370(9596):1453-1457.
44. Csuka M, McCarty DJ. Simple method for measurement of lower extremity muscle strength. Am J Med 1985;78(1):77-81.

45. Whitney SL, Wrisley DM, Marchetti GF, Gee MA, Redfern MS, Furman JM. Clinical measurement of sit-to-stand performance in people with balance disorders: validity of data for the five-times-sitto-stand test. Phys Ther 2005;85(10):1034-1045.

46. Millor N, Lecumberri P, Gomez M, Martinez-Ramirez A, Izquierdo M. Kinematic parameters to evaluate functional performance of sitto-stand and stand-to-sit transitions using motion sensor devices: a systematic review. IEEE Trans Neural Syst Rehabil Eng 2014;22(5): 926-936.

47. Janssen WG, Bussmann JB, Horemans HL, Stam HJ. Validity of accelerometry in assessing the duration of the sit-to-stand movement. Med Biol Eng Comput 2008;46(9):879-887.

48. Moreira FBR, de Lucena Panka GF, Vieira DSR, Faria LM, Velloso M. Functional evaluation instruments in patients with chronic obstructive pulmonary disease: a review of the literature. J Respir Cardiovasc Phys Ther 2013;1(2):59-66.

49. Graham JE, Ostir GV, Kuo YF, Fisher SR, Ottenbacher KJ. Relationship between test methodology and mean velocity in timed walk tests: a review. Arch Phys Med Rehabil 2008;89(5):865-872.

50. Schwenk M, Gogulla S, Englert S, Czempik A, Hauer K. Test-retest reliability and minimal detectable change of repeated sit-to-stand analysis using one body fixed sensor in geriatric patients. Physiol Meas 2012;33(11):1931-1946.

51. Hughes MA, Myers BS, Schenkman ML. The role of strength in rising from a chair in the functionally impaired elderly. J Biomech 1996;29(12):1509-1513.

52. Hardy R, Cooper R, Shah I, Harridge S, Guralnik J, Kuh D. Is chair rise performance a useful measure of leg power? Aging Clin Exp Res 2010;22(5-6):412-418.

53. McCarthy EK, Horvat MA, Holtsberg PA, Wisenbaker JM. Repeated chair stands as a measure of lower limb strength in sexagenarian women. J Gerontol A Biol Sci Med Sci 2004;59(11):1207-1212.

54. Lord SR, Murray SM, Chapman K, Munro B, Tiedemann A. Sit-tostand performance depends on sensation, speed, balance, and psychological status in addition to strength in older people. J Gerontol A Biol Sci Med Sci 2002;57(8):M539-M543.

55. Netz Y, Ayalon M, Dunsky A, Alexander N. 'The multiple-sit-tostand' field test for older adults: what does it measure? Gerontology 2004;50(3):121-126

56. Jones CJ, Rikli RE, Beam WC. A 30-s chair-stand test as a measure of lower body strength in community-residing older adults. Res Q Exerc Sport 1999;70(2):113-119.

57. Bernabeu-Mora R, Medina-Mirapeix F, Llamazares-Herran E, Oliveira-Sousa SL, Sanchez-Martinez MP, Escolar-Reina P. The accuracy with which the 5 times sit-to-stand test, versus gait speed, can identify poor exercise tolerance in patients with COPD: a crosssectional study. Medicine 2016;95(35):e4740.

58. Pitta F, Troosters T, Spruit MA, Probst VS, Decramer M, Gosselink R. Characteristics of physical activities in daily life in chronic obstructive pulmonary disease. Am J Respir Crit Care Med 2005;171(9): 972-977.

59. Chorin F, Rahmani A, Beaune B, Cornu C. Determination of reliable force platform parameters and number of trial to evaluate sit-to-stand movement. Aging Clin Exp Res 2015;27(4):473-482.

60. Ng SS, Cheung SY, Lai LS, Liu AS, Ieong SH, Fong SS. Five times sit-to-stand test completion times among older women: influence of seat height and arm position. J Rehabil Med 2015;47(3):262-266.

61. Ng SS, Cheung SY, Lai LS, Liu AS, Ieong SH, Fong SS. Association of seat height and arm position on the five times sit-to-stand test times of stroke survivors. Biomed Res Int 2013;2013;642362. 